\title{
Foot complications among diabetics attending a district hospital in Kenya: Predisposing factors and possible intervention
}

\begin{abstract}
M.M. Obimbo, MBChB, P.K. Bundi, BSc (Anat) and F. Collis, MSSCh, Dip. PodMed, MBChB, J.A. Ogeng'o, BSc (Anat), MBChB, PhD, Department of Human Anatomy, School of Medicine, University of Nairobi, P.O. Box 30197-00100, Nairobi, Kenya

Correspondence and reprint requests to:

Dr. M.M. Obimbo, Department of Human Anatomy, School of Medicine, University of Nairobi, P.O. Box 30197-00100, Nairobi, Kenya. Email: obimbo24@yahoo.com
\end{abstract}

\section{Abstract}

OBJECTIVES: To relate skin health, footwear practices and foot care education with occurrence of foot complications among diabetics attending a district hospital in Kenya.

PATIENTS AND METHODS: Two hundred and nineteen patients attending the diabetic clinic at the Kikuyu Mission Hospital (99 males, 120 females) were studied. They were examined for the presence, type and cause of foot complication, skin health, education on foot care and footwear.

RESULTS: Twenty nine point two percent of the patients had foot complications, with 95\% of these presenting with diabetic ulcer, the rest had Charcot's foot or cellulitis. The diabetic foot ulcer was traumatic in $75.4 \%$ and spontaneous in $24.6 \%$. Fifty seven percent of the patients had risky footwear, associated with development of foot ulcer $(p=0.001)$. Ninety eight percent of the patients with foot complications had either atrophic or dry skin $(p=0.001)$. Fifty two point four percent had not received foot care education, with males who had received education being more than females $(\mathrm{p}=0.05)$.

CONCLUSION: The rate of foot complications among diabetics is higher than previously observed. Diabetic foot ulcer, the commonest complication, is mostly traumatic. Patients with foot care education, proper footwear and good skin health had lower incidence of traumatic diabetic foot ulcer. Dissemination of foot care education and use of right footwear for diabetics may reduce the incidence of complications.

\section{Introduction}

Uncontrolled Diabetes Mellitus (DM) is associated with a wide range of complications, some of which require surgical attention (1). About $10 \%$ of diabetic patients develop foot complications (2). These include foot ulcer, Charcot's foot and diabetic cellulitis $(3,4)$. The increase in foot complications in diabetics may be directly related to foot wear practices, skin health and foot care education.

In the developed world, emphasis on the use of appropriate foot wear for diabetics is almost universal $(5,6)$, and issues of compliance are now a priority (8). Skin complications in DM largely result from the combined effect of hyperglycaemia, neuropathy, microvascular and macrovascular angiopathies. Poor skin care, with attendant infections, increases the risk of developing diabetic foot ulcers and cellulitis (8). 
This is the subject of extensive foot education and foot care campaigns in developed countries (10). Little is known about foot wear, skin health and foot care education and their relationship to foot complications among diabetics in Kenya.

This study investigated the relationship between diabetic foot complications and foot care education, skin health and footwear practices in patients attending a diabetic clinic in a Kenyan District Hospital.

\section{Patients and methods}

Two hundred and nineteen consenting patients with the diagnosis of diabetes mellitus attending the Kikuyu Mission Hospital between $1^{\text {st }}$ June and $1^{\text {st }}$ September 2007 were recruited. Ethical approval was sought from the Kikuyu Mission Hospital Management Board. Patients were free to opt out of the study once recruited. The pre-study estimate of proportion was obtained from a previous study that employed a similar method as this study. Patients who already had amputations and those younger than twenty years of age were excluded from the study. Patients were identified and interviewed by the specialized clinical officers, nurses and medical officers working in the diabetic unit, the medical and surgical wards. Patients were interviewed on the level of their diabetic education as follows:

\section{Question}

\begin{tabular}{|l|l|}
\hline What is diabetes? & $\begin{array}{l}\text { Correct response given } \\
1 \text { mark }\end{array}$ \\
\hline $\begin{array}{l}\text { Name two complications } \\
\text { of diabetes }\end{array}$ & $\begin{array}{l}\text { Any two correct } \\
\text { responses } 2 \text { marks }\end{array}$ \\
\hline $\begin{array}{l}\text { Is foot ulcer one of the } \\
\text { diabetes complications? }\end{array}$ & $\begin{array}{l}\text { Given 1 mark for } \\
\text { correct response }\end{array}$ \\
\hline $\begin{array}{l}\text { Give two ways of } \\
\text { preventing foot ulcers in } \\
\text { diabetic patients }\end{array}$ & $\begin{array}{l}\text { Given } 2 \text { marks for any } \\
\text { two correct response }\end{array}$ \\
\hline
\end{tabular}

Patients who scored four out of six marks were considered to be educated on diabetes and foot care. They were asked on their footwear practices at home and the place of work through making inquiries whether they put on shoes while at home and to state which kind of shoes they put on; flip-flops, sandals or closed rubber/ leather shoes. The former were considered risky whereas the latter were considered appropriate. Patient footwear at the time of examination was classified as appropriate (if the shoe fit the patient adequately and no excessive pressure was applied on the feet) or inappropriate. The patients were asked for the duration of DM and the cause of foot ulcers - whether spontaneous or traumatic. Patients' files were scrutinized for co-morbid conditions such as peripheral neuropathy, hypertension and skin health. Skin health was classified as atrophic if the foot skin was wrinkled with exaggerated bony prominences; dry if fissures were observed and normal if healthy. Diabetic ulcer, Charcot's foot and cellulitis were examined for their magnitude, anatomical location and bilateral differences. Vascular assessment was done, with the pulses of anterior, posterior tibial and the dorsalis pedis classified as either triphasic (strong), biphasic (weak), monophasic (very weak). Statistical analysis was done using the Statistical Programme for Social Sciences (SPSS) version 11.50, Chicago, Illinois (for windows). A value of $P<0.05$ was considered significant. Results are expressed as proportions.

\section{Results}

Two hundred and nineteen patients were studied (99 males and 120 females). Fifty four percent of the patients were over the age of sixty years the rest were below sixty. Sixty four patients $(29.2 \%)$ had foot complications, with $96.5 \%$ of them presenting with diabetic ulcer while the rest had diabetic cellulitis and Charcot's foot.

One hundred and fifty seven patients $(90.2 \%)$ had sensory neuropathy. The diabetic foot ulcer was traumatic in $75.4 \%$ and spontaneous in $24.6 \%$. Majority of the patients with diabetes had hypertension as a co-morbid condition $(57 \%)$. Many of the patients who took part in the study ( $43 \%)$ had short duration ( $0-5$ years) after diagnosis. Many of the patients who had associated foot complication had also a shorter duration of diabetes from the time of diagnosis $(\mathrm{p}=0.02)$. 
Thirty six percent (Table 1) of the patients studied had very weak to weak pulses of the anterior tibial, posterior tibial and dorsalis pedis arteries. Ninety eight percent of the patients with foot complications had poor skin health defined as either atrophic or dry, and this was significant $(p<0.001)$. Fifty seven percent of the patients had risky footwear and this was directly related to the presence of foot ulcers $(p=0.001)$. Fifty two point four percent had not received foot care education, with males who had received being more than females $(\mathrm{p}$ $=0.05$ ). There was no correlation between foot care education and presence of diabetic cellulitis and Charcot's foot (Table 2).

Table 1: Summary of biodata of diabetic patients

\begin{tabular}{llcc} 
& Description & No. & $(\%)$ \\
Age (years) & $20-60$ & 100 & 46 \\
Sex & $>60$ & 119 & 54 \\
& Male & 99 & 45 \\
Foot complication & Female & 120 & 55 \\
& None & 155 & 70.7 \\
& Diabetic Ulcer & 61 & 27.9 \\
Footwear practice & Diabetic cellulitis & 2 & 0.9 \\
& Charcot's foot & 1 & 0.4 \\
Foot care education & Risky & 77 & 35.2 \\
Skin health & Appropriate & 142 & 64.8 \\
& Yes & 104 & 47.6 \\
Neripheral pulses & No & 115 & 52.4 \\
& Atrophic & 6 & 2.8 \\
& Dry & 102 & 46.9 \\
\hline
\end{tabular}

Majority of the patients with ulcers were females $(60 \%)$ and most of the ulcers $(67 \%)$ were located on the right foot $(\mathrm{P}=0.003)$.

Table 2: Predisposing factors to foot complications amongst diabetics

\begin{tabular}{|c|c|c|c|c|c|}
\hline Description & & No. with complications & No. without complications & P-value & (OR) \\
\hline Age & $\begin{array}{l}20-60 \text { years } \\
>60 \text { years }\end{array}$ & $\begin{array}{l}24 \\
39\end{array}$ & $\begin{array}{l}70 \\
73\end{array}$ & 0.149 & 1.1 \\
\hline Duration of DM & $\begin{array}{l}0-5 \text { years } \\
>5 \text { years }\end{array}$ & $\begin{array}{l}20 \\
18\end{array}$ & $\begin{array}{l}72 \\
73\end{array}$ & 0.017 & 1.2 \\
\hline Gender & $\begin{array}{l}\text { Male } \\
\text { Female }\end{array}$ & $\begin{array}{l}25 \\
38\end{array}$ & $\begin{array}{l}64 \\
81\end{array}$ & 0.55 & 1.0 \\
\hline Footwear & $\begin{array}{l}\text { Appropriate } \\
\text { Risky }\end{array}$ & $\begin{array}{l}22 \\
40\end{array}$ & $\begin{array}{c}120 \\
37\end{array}$ & 0.001 & 1.73 \\
\hline Footcare education & $\begin{array}{l}\text { Yes } \\
\text { No }\end{array}$ & $\begin{array}{l}28 \\
35\end{array}$ & $\begin{array}{l}69 \\
76\end{array}$ & 0.67 & 1.0 \\
\hline Skin & $\begin{array}{l}\text { Abnormal } \\
\text { Normal }\end{array}$ & $\begin{array}{l}58 \\
85\end{array}$ & $\begin{array}{l}44 \\
17\end{array}$ & $<0.001$ & 1.5 \\
\hline Sensory neuropathy & $\begin{array}{l}\text { Present } \\
\text { Absent }\end{array}$ & $\begin{array}{c}54 \\
9\end{array}$ & $\begin{array}{c}138 \\
8\end{array}$ & 0.03 & 1.5 \\
\hline $\begin{array}{l}\text { Co-morbidity } \\
\text { (Hypertension) }\end{array}$ & $\begin{array}{l}\text { Yes } \\
\text { No }\end{array}$ & $\begin{array}{l}39 \\
23\end{array}$ & $\begin{array}{l}80 \\
66\end{array}$ & 0.28 & 0.9 \\
\hline
\end{tabular}

$\mathrm{OR}=$ Odds ratio 
Figure 1: Presentations of various diabetic foot complications.
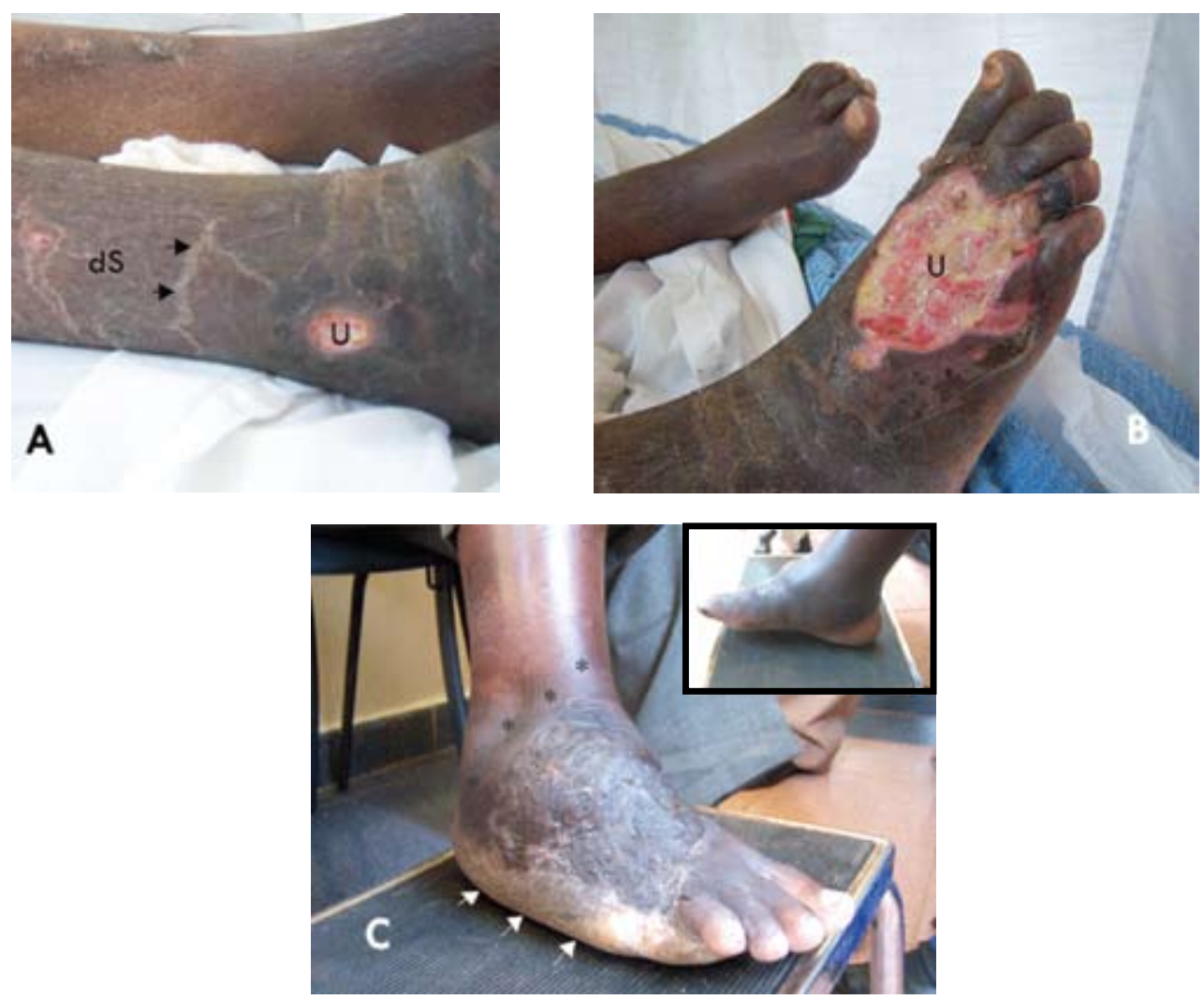

dS: dry skin; U: ulcer. Note the cracked skin (A arrowheads), oedematous foot (C, astericks) and collapsed plantar arch of Charcot's foot (C, arrows)

\section{Discussion}

In contrast to previous reports using nearly similar methods, we found a higher incidence of diabetic foot ulcer (Table 3). The disparity could be attributed to differences in the selected population group. The study by Nyamu et al, (12) used a larger population sample while those in the USA and India possibly involved patients who used proper foot wear and were educated on foot care $(10,11,13)$.

Table 3: Incidences of diabetic foot ulcer in several populations

\begin{tabular}{lcc}
\hline Author & Study population & $\begin{array}{c}\text { Prevalence of } \\
\text { diabetic ulcer }\end{array}$ \\
\hline Ramsey et al, 1999 & USA & $5.8 \%$ \\
BRFSS, USA, 2000 & USA & $11.8 \%$ \\
Nyamu et al, 2003 & KENYA & $4.6 \%$ \\
Singh et al, 2005 & INDIA & $4-10 \%$ \\
Present study & KENYA & $27.9 \%$ \\
\hline
\end{tabular}

Foot ulceration was the most common complication similar to previous observations (4). As expected, the occurrence of the foot ulcer was proportionate to the prevalence of sensory neuropathy (14). The prevalence of neuropathy is however much higher $(90.2 \%)$, than reported rates in African countries (15) (Table 4).

Sensory neuropathy can be explained by the levels of glycemic control (16) with individuals having tight control less prone to developing neuropathy. The high prevalence observed here could be an indicator of poor glycemic control.

The foot ulcers were mainly traumatic, similar to other studies which have shown trauma to be a significant cause of foot ulcers (17). In the few cases where the patients did not report trauma, sensory neuropathy could be the explanation. Skin health amongst patients with foot ulcers was either atrophic or dry. This result was not surprising as more foot complications would be expected 
Table 4: Peripheral neuropathy in diabetics: Abbas and Archibald, 2007

\begin{tabular}{lllcl} 
Publication year & Author & Country & No. & $\begin{array}{c}\text { Prevalence of peripheral } \\
\text { sensory neuropathy (\%) }\end{array}$ \\
\hline Present day & Obimbo et al & Kenya & 219 & 90.2 \\
2003 & Moulik et al & Zambia & 185 & 61 \\
2000 & Abbas et al & Tanzania & 200 & 25.5 \\
1996 & Nambuya et al & Uganda & 252 & 46.6 \\
1992 & Lester & Ethopia & 431 & 8 \\
1991 & Friend et al & Malawi & 100 & 59 \\
1989 & El Mahdi et al & Sudan & 413 & 28.1 \\
1963 & Gelfande et al & Zimbabwe & 99 & 4 \\
1976 & Adetuyibi & Nigeria & 52 & 69.6 \\
\hline
\end{tabular}

in individuals with poor skin health. The factors which contribute to poor skin health include hyperglycaemia, neuropathy, and both microvascular and macrovascular angiopathies (8).

We found a low incidence of diabetic cellulitis and Charcot's foot similar to previous studies carried out by Lavery et al, (18) who found an incidence of $1.7 \%$. Most recent data, however, suggest that the infection rate could have risen to $4.5 \%$ (19). This study found no association with foot care education.

A significant number of patients were found to have had risky footwear. Walking barefoot or using rubber flip-flops increases the risk of foot trauma (20). Poverty has also been reported to be associated with development of foot ulceration (21). Poor people may not be able to purchase appropriate footwear. Although many of the patients studied reported that they put on the flip flops and sandals (risky) while at home; financial constraints as the cause of the behaviour was not pursued.

Hypertension was the commonest co-morbid just as reported in literature (22). A combination of cardiovascular disease and diabetes increases the risk of foot complications. Approximately $33 \%$ of our patients had a monophasic to biphasic pulses suggesting an at-risk population for peripheral vascular disease. Recent data suggest that the peripheral vascular disease is an increasing problem amongst diabetic patients in African countries (21).

There was a weak association between foot care education and foot complications. Stronger association has been reported elsewhere (23). The difference could be attributed to sample sizes. The present study found an association between skin health and ulceration in keeping with previous studies (24).

In conclusion, the incidence of foot ulcers is high at Kikuyu Mission Hospital. Inappropriate footwear was an important antecedent factor preceding the occurrence of the foot ulcer. Vigorous campaigns including foot wear education and promotion of healthy lifestyle may prevent the escalation of the complications.

\section{Acknowledgements}

To the staff of the Diabetic Clinic and administration of Kikuyu Mission Hospital. Many thanks to Dr. S. Hassan for positive critique. Prof. P. Jani and Mr. K.W. Ongeti for advice during the development of the concept.

\section{References}

1. Pecoraro R.E., Reiber G.E. and Burgess E.M. Pathways to diabetic limb amputation. Basis for prevention. Diabetes Care. 1990; 13(5): 513-521.

2. Rieber G.E. The epidemiology of diabetic foot problems. Diabetic Med. 1996; 16: 245-249.

3. Rajbhandari R., Jenkins R., Davies C. et al. Charcot neuroarthropathy in diabetes mellitus: Diabetologia, 2002; 45: 8 .

4. Frykberg R.G. Diabetic foot ulcers: Pathogenesis and management. Amer. Fam. Physician. 2002; 66: 1655-1662.

5. Tovey F.I. The manufacture of diabetic footwear: Diabet. Med. 1984; 1: 69-71.

6. Schaff P.S. and Cavanagh P.R. Shoes for the insensitive 
foot: The effect of Rockerbottom: shoe modification on plantar pressure distribution. Foot and Ankle. 1990; 11: 129 .

7. Litzelman D.K., Marriott D.J. and Vinicor F. The role of footwear in the prevention of foot lesions in patients with non-insulin dependent diabetes mellitus: Conventional wisdom or evidence-based practice. Diabetes Care. 1997; 20(2): 156-162.

8. Lai C.F. Cutaneous manifestations in Diabetes Mellitus. Hong Kong Practioner. 1992; 14(5): 2060-2065.

9. National diabetes information clearinghouse national institute for diabetes and digestive and kidney diseases handbook, 2007. www.diabetesniddk.nih.gov

10. Ramsey S.D., Newton K., Blough D., et al. Incidence, outcomes, and cost of foot ulcers in patients with diabetes. Diabetes Care. 1999; 3: 382-387.

11. Behavioural risk factor surveillance system (BRFSS). Lower extremity amputations episodes among persons with diabetes. New Mexico. 2000. www.cdc. gov/MMWR/preview.

12. Nyamu P.N., Otieno C.F., Amayo E.O. et al. Risk factors and prevalence of diabetic foot ulcers at Kenyatta National Hospital, Nairobi. East Afr. Med. J. 2003; 80: 36-43.

13. Singh N, M.D., Armstrong D.G. and Lipsky B.A. Preventing foot ulcers in patients with diabetes. JAMA. 2005; 293: 217-228.

14. McLarty D.G., Kinabo L. and Swai A.B.M. Diabetes in tropical Africa: A prospective study, 1981-7. II. Course and prognosis. BMJ. 1990; 300: 1107-1110.

15. Abbas Z.G. and Archibald L.K. The diabetic foot in sub-Saharan Africa: A new management paradigm. Diabet. Foot J. 2007; 10: 128-134.

16. Adler A.I., Boyko E.J., Ahroni J.H., et al. Risk factors for Diabetic Sensory neuropathy. Results of the Seattle prospective Diabetic Foot Study. Diabetes Care. 1997; 20(7): 1162-1167.

17. Loretta V. Diabetic foot ulcers: A quality of life issue Diabetes/metabolism research and reviews, 2001; 17: 246-249.

18. Lavery L.A., Armstrong D.G., Wunderlich R.P., et al. Predictive value of foot pressure assessment as part of a population-based diabetes disease management program. Diabetes Care. 2003; 26: 1069-1073.

19. Lipsky B.A. Diabetic foot infections: microbiology made modern? A ray of hope Diabetes Care, 2007; 30: 2171-2172.

20. Rolfe M., Tang C.M. and Walker R.W. Diabetes mellitus in The Gambia, West Africa. Diabetic Med. 1992; 9: 484-488.

21. Abbas Z.G., Lutale J., Archibald L.K. Rodent bites on the feet of diabetes patients in Tanzania. Diabet. Med. 2005; 22: 631-633.

22. Watkins P. ABC of Diabetes: Cardiovascular disease, hypertension and lipids. BMJ. 2003; 326: 874-876.

23. Chanda A., Ayyar V., Idiculla J.M. et al. Perception of foot problems among diabetic patients: A cross sectional study. Int. J. Diab. Dev. Ctries. 2006; 26: 77-80.

24. American Podiatric Medical Association, 2007. http://advfac.com/Documents/Foot20Self-Eval.pdf 